\title{
Optimising biogas from food waste using a neural network model
}

1 Duraisamy Palaniswamy Dipl Eng, BEng, MEng, PhD Associate Professor, Department of Mechanical Engineering, Adithya Institute of Technology, Coimbatore, Tamil Nadu, India (corresponding author: 131ems@gmail.com)

2 Gurusamy Ramesh BEng, MEng, PhD Principal, Department of Mechanical Engineering, JCT College of Engineering and Technology, Coimbatore, Tamil Nadu, India
B Subbarayan Sivasankaran BE, MTech, PhD Assistant Professor, Department of Mechanical Engineering, College of Engineering, Qassim University, Buraydah, Kingdom of Saudi Arabia

5 Nanjundan Kathiravan BEng, MEng, PhD Principal, Department of Mechanical Engineering, Adithya Institute of Technology, Coimbatore, Tamil Nadu, India
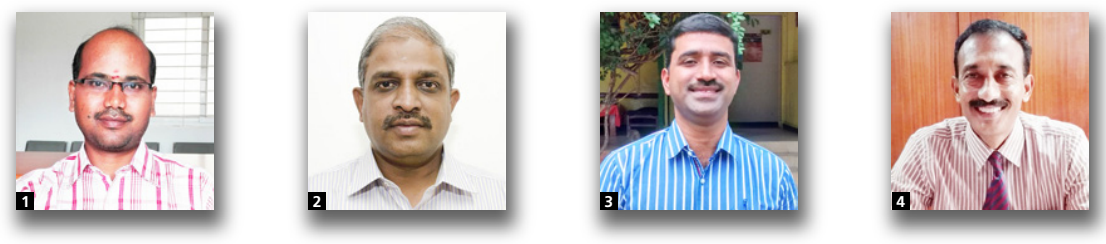

This study has been carried out to investigate the production of biogas by anaerobic digestion of solid-phase kitchen food waste using an artificial neural network. The network was used to model and optimise biogas production using mixed substrates of food waste with cow dung. The substrate mix percentage, plant pH level, digestion period and digester temperature were used as input parameters for the model, with biogas yield as the output. Food waste and cow dung were mixed at different compositions to a total mass of $\mathbf{2} \mathbf{~ k g}$ and placed in 21 miniature digesters. The input and output parameters from the digesters were then considered in the model. The highest biogas performance level of $375 \mathrm{ml} / \mathrm{g}$ volatile solids on the 25 th day of digestion was achieved by a substrate profile of $80 \%$ food waste and $20 \%$ cow dung at a temperature range of $30-40{ }^{\circ} \mathrm{C}$. On the basis of these results, kitchen food waste is shown to be highly biodegradable and an effective source of biogas.

\section{Introduction}

In India, $\sim 25-35 \%$ of household food wastes constitute junk wastes. The most common methods of managing food waste are by land filling and it requires a huge area whereas firing the waste consumes more energy and it pollutes the environment. Another way of treating food waste is by recycling; this can possibly reduce the cost of waste treatments, odours, reduces landfills and air pollutants due to the burning/ incineration process and so on. In recycling, the food wastes are converted into biomethane by way of anaerobic digestion and many studies have been carried out worldwide (Bajon Fernandez et al., 2014; Curry and Pillay, 2012; Mezzullo et al., 2013). The organic content is broken down at the basic level in the process of anaerobic digestion, thereby generating gas, which is known as biogas. Microorganisms assist the digestion process and the anaerobic fermentation produces carbon dioxide $\left(\mathrm{CO}_{2}\right)$, methane $\left(\mathrm{CH}_{4}\right)$, hydrogen $\left(\mathrm{H}_{2}\right)$ and traces of other gases along with decomposed mass (Bajon Fernandez et al., 2014; Middleton and Eccles, 2013).

The food waste and cow dung are the substrates that have been reported to increase the yield of biogas production by more than 44\% (Avicenna et al., 2015; Rongpin et al., 2009). Biogas production by fermentation of bio-products is influenced by the genetic nature of organism, fermentation factors, physiological conditions, nature of the substrate material and also by the nature of the bioreactor that is used for production (Kumar et al., 2009; Lai et al., 2009). The resultant biogas production is controlled by the substrate sources and concentration, $\mathrm{pH}$ levels, architectural set-up of the reactor and fermentation temperature (Hanreich et al., 2013; Labatut et al., 2014; Sitorus et al., 2013; Stantscheff et al., 2014; Trisakti et al., 2015). It has been well accepted that maintenance of an optimised fermentative environment is one of the most 


\begin{tabular}{|c|c|c|c|c|}
\hline \multirow[b]{2}{*}{ Source } & \multicolumn{3}{|c|}{ Characteristics } & \multirow[b]{2}{*}{ Country } \\
\hline & MC: \% & VS/TS: \% & $C / N$ & \\
\hline A dining hall & 80 & 95 & $14 \cdot 7$ & Korea \\
\hline University's cafeteria & 80 & 94 & NA & Korea \\
\hline A dining hall & 93 & 94 & $18 \cdot 3$ & Korea \\
\hline A dining hall & 84 & 96 & NA & Korea \\
\hline Mixed municipal sources & 90 & 80 & NA & Germany \\
\hline Mixed municipal sources & 74 & $90-97$ & NA & Australia \\
\hline $\begin{array}{l}\text { Emanating from fruit and vegetable markets, } \\
\text { household and juice centres }\end{array}$ & 85 & 89 & $36 \cdot 4$ & India \\
\hline
\end{tabular}

NA, not available; MC, moisture content; TS, total solids

Table 1. Characteristics of food wastes reported in the literature

essential factors for improved biogas yield (Prakasham et al., 2009; Wang and Wan, 2009). The carbon to nitrogen $(C / N)$ ratio for optimal biogas production should be in the range of 25-30. The characteristics of food wastes are given in Table 1 as previously described (Zhang et al., 2007). With the above reference, it is noted that in dining waste the $C / N$ ratio is from 14.7 to 18.3 and the $C / N$ ratio of vegetable and fruit waste is 36.4. Hence, the mixture of food waste, vegetable waste will have a $C / N$ ratio of 25 , which will be optimal for biodegradation of the raw resources since a high $C / N$ ratio would have an effect on this process. Temperature also serves as a major factor in digesting food waste. The optimal temperature range of the mesophilic reaction is $30-38^{\circ} \mathrm{C}$ and that of the thermophilic reaction is $44-57^{\circ} \mathrm{C}$ (Tchobanoglous and Burton, 1991). Most of the digesters now operate at mesophilic temperatures (Hanreich et al., 2013; Stantscheff et al., 2014), with good stability and gas production. Therefore, mesophilic digestion was chosen for the study and it was carried out with ease which is the optimal temperature in India.

Mathematical models are more useful in providing information on the interactive behaviour of various factors in different types of fermentation (Martinez et al., 2012; Wichern et al., 2009). Compared with the conventional methods, optimisation by considering 'one-factor-at-a-time' is effective as it does not depict the combined effect of all the factors involved in particular complicated bioprocesses. In recent years, artificial neural network (ANN) has been successfully applied in multivariate non-linear bioprocesses as a useful tool to construct models and to predict outputs accurately for new input data sets (Haider et al., 2008; Vijay and Rintu, 2010). ANN is an empirical model and a very powerful tool, which is symmetrical to the deportment of biological neural structures and effectively represents complex non-linear systems. It is also considered as a non-linear statistical identification technique

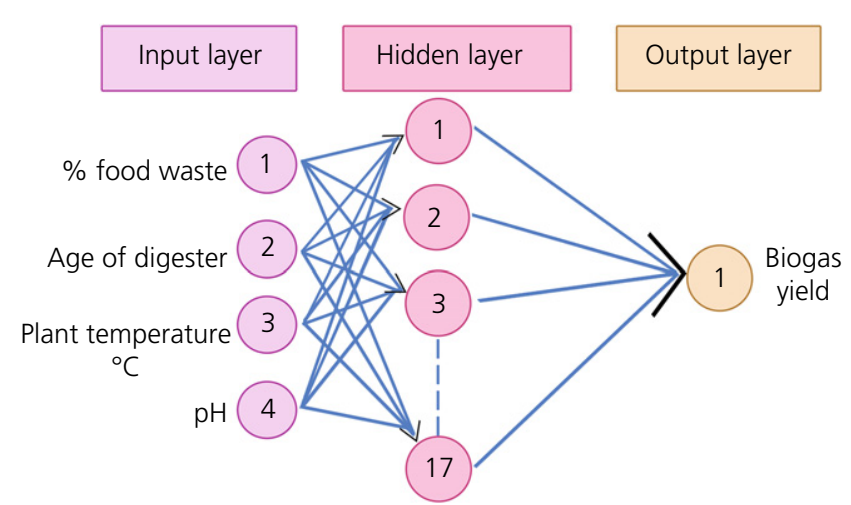

Figure 1. Configuration of multilayer neural network for predicting excessive biogas production

(Abu Qdais et al., 2010; Gueguim Kana et al., 2012; Prakasham et al., 2011).

In this study, ANN has been used in obtaining the best optimised environment for the fermentation of food wastes and biogas production. In this model, four imperative input parameters were used for the composition of food waste and cow dung, plant $\mathrm{pH}$ level, age of the plant and temperature, while the output parameter is the biogas yield. The represented input and output collection of data are shown in Figure 1.

\section{Materials and methods}

\subsection{Experimental procedure}

The experimental study was carried out at Adithya Institute of Technology in Energy Engineering Laboratory. The food waste collected includes a mixture of boiled rice, wheat breads, 
vegetable peelings and vegetable wastes. The cow dung was mixed with the food wastes to a total weight of $2 \mathrm{~kg}$ at various compositions in the 21 digesters each of 5 litre capacity. The mixed proportions of food waste and cow dung with different compositions in the -21 digesters are shown in Table 2. The $\mathrm{pH}$ value during the digestion period was measured using the $\mathrm{pH}$ tape. The readings were taken from the 15 th day of digestion up to 45th day with the $\mathrm{pH}$ ranging from 6 to 8 noted. The pilot digester plant temperature was monitored at regular intervals and the temperature recorded. The quantity

\begin{tabular}{|c|c|c|c|c|c|}
\hline \multirow{2}{*}{$\begin{array}{l}\text { Sl. } \\
\text { number }\end{array}$} & \multirow{2}{*}{$\begin{array}{l}\text { Pilot digester } \\
\text { plant }\end{array}$} & \multicolumn{2}{|c|}{ Food waste } & \multicolumn{2}{|c|}{ Cow dung } \\
\hline & & Weight: $g$ & $\%$ & Weight: g & $\%$ \\
\hline 1 & Digester 1 & 0 & 00 & 2000 & 100 \\
\hline 2 & Digester 2 & 100 & 05 & 1900 & 95 \\
\hline 3 & Digester 3 & 200 & 10 & 1800 & 90 \\
\hline 4 & Digester 4 & 300 & 15 & 1700 & 85 \\
\hline 5 & Digester 5 & 400 & 20 & 1600 & 80 \\
\hline 6 & Digester 6 & 500 & 25 & 1500 & 75 \\
\hline 7 & Digester 7 & 600 & 30 & 1400 & 70 \\
\hline 8 & Digester 8 & 700 & 35 & 1300 & 65 \\
\hline 9 & Digester 9 & 800 & 40 & 1200 & 60 \\
\hline 10 & Digester 10 & 900 & 45 & 1100 & 55 \\
\hline 11 & Digester 11 & 1000 & 50 & 1000 & 50 \\
\hline 12 & Digester 12 & 1100 & 55 & 900 & 45 \\
\hline 13 & Digester 13 & 1200 & 60 & 800 & 40 \\
\hline 14 & Digester 14 & 1300 & 65 & 700 & 35 \\
\hline 15 & Digester 15 & 1400 & 70 & 600 & 30 \\
\hline 16 & Digester 16 & 1500 & 75 & 500 & 25 \\
\hline 17 & Digester 17 & 1600 & 80 & 400 & 20 \\
\hline 18 & Digester 18 & 1700 & 85 & 300 & 15 \\
\hline 19 & Digester 19 & 1800 & 90 & 200 & 10 \\
\hline 20 & Digester 20 & 1900 & 95 & 100 & 05 \\
\hline 21 & Digester 21 & 2000 & 100 & 0 & 00 \\
\hline
\end{tabular}

Table 2. Plant operating substrate profiles evaluated experimentally of biogas produced was measured using the water displacement method.

The biogas sample was analysed periodically using the gas chromatograph (SHIMADZU - GC 2014) equipped with a thermal conductivity detector (TCD 2014) and flame photometric detector 2014 with quartz glass nozzle packed. These detectors were used for the analysis of organic sulfur compounds and the organic phosphorus compounds such as residual pesticides and malodorous components. The digesters with a composition of $0,25,50,75$ and $100 \%$ food waste were selected and the constituents are given in Table 3.

\subsection{ANN design and training}

In this study, a total data set of 546 numbers of results among which a two-third data set of 364 numbers has been considered for training in $\mathrm{ANN}$, and the remaining data set of 182 numbers for testing in ANN. The input/output data set was normalised within the range of \pm 1 before training the network. The standard multilayer feed-forward and backward propagation hierarchical neural networks (BPNN) are designed in the 'MATLAB 2008a Neural Network Toolbox'. This network consists of three layers: an input layer, a hidden layer and an output layer as shown in Figure 1.

The number of iterations (epochs) to be executed is an important parameter in the case of BPNN training. Initially, there are four neurons in the input layer, three neurons in the hidden layer and one neuron in the output layer (4-3-1). This construction is taken for training and it is carried out with different numbers of epochs to find the best iterations. The mean square error (MSE) achieved from different iterations are shown in Figure 2. It is evident that the values of MSE regularly decrease during the progress of training. An inaccuracy of 0.00218 at 10 epochs, 0.00152 at 50 epochs is reduced to 0.0006136 after 100 iterations, and not much change has been found with further increase in the number of iterations. The output is qualified with different architecture by varying the number of neurons in the hidden layer(s).

\begin{tabular}{llccccc}
\hline Sl. number & Constituent & Digester 1 & Digester 6 & Digester 11 & Digester 16 & Digester 21 \\
\hline 1 & Methane: \% & 70 & 67 & 62 & 58 & 55 \\
2 & Carbon dioxide: \% & 25 & 28 & 33 & 36 & 38 \\
3 & Hydrogen sulfide: \% & 1.8 & 2 & 2.4 & 3.1 & 4 \\
4 & Nitrogen: \% & 1.01 & 0.99 & 0.98 & 0.94 & 0.84 \\
5 & Hydrogen: \% & 0.98 & 0.91 & 0.88 & 0.72 & 0.68 \\
6 & Carbon monoxide: \% & 0.18 & 0.24 & 0.39 & 0.61 & 0.74 \\
7 & Oxygen: \% & 0.08 & 0.08 & 0.07 & 0.08 & 0.06
\end{tabular}

Table 3. Partial sample constituent composition of biogas 


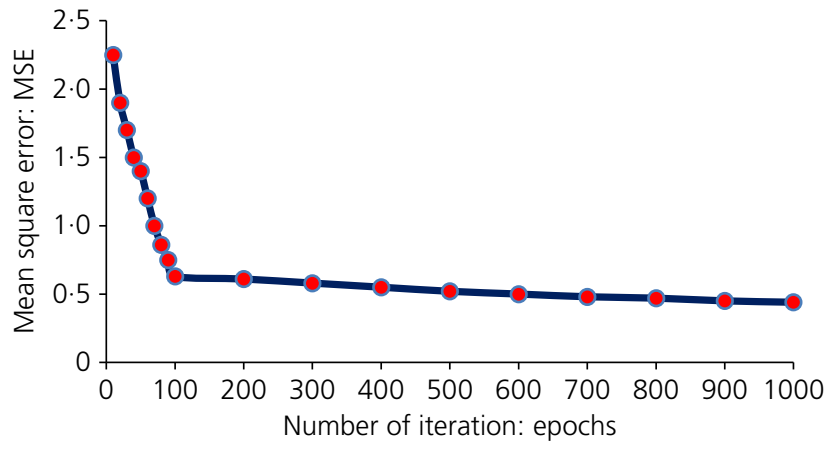

Figure 2. Variation of the MSE of the trained data as a function of epochs

To find out the optimal architecture, 30 different networks with different number of layers of neurons in the hidden layer were designed and tested. The BPNN architecture is a technique that can be efficiently used to predict the biogas yield from a mixture of food waste and cow dung; a different multilayer BPNN architecture was also trained and used. The BPNN with one unseen layer having 17 neurons, trained with Levenberg-Marquardt algorithm, was found to be the optimum network model for biogas yield (4-17-1).

\section{Results and discussion}

The foremost idea of the current work is to study, anticipate and analyse the biogas yield due to the effect of composition of food waste and cow dung using BPNN analysis. The biogas yield is evaluated by the plant $\mathrm{pH}$ level, age of the plant and temperature condition.

\subsection{Testing and performance of the BPNN}

The performance value of each network is examined based on the association of coefficient, error distribution and convergence of the entire data set within the specified error range which lies between the network prediction and the experimental values using the test and entire data set. To resolve the optimum arrangement of neural network, the rate of blunder junction is investigated by changing the number of secret neurons and the number of hidden layers. From Table 4, the hidden neurons are identified and the networks with a single hidden layer of 17 neurons have given a correlation coefficient of 0.9996 and mean error of $0.0036 \%$ which means that the error distribution is uniform. Further, it is observed that $98.97 \%$ of the entire data set is within $\pm 4 \%$ error (Table 5 ). Moreover, the increase in the number of neurons in the single hidden layer (beyond 17) and the error allocation is not uniform (Table 4). Hence, it has been decided and concluded that the selection of optimum architecture depends on the mean error $\%$, maximum error $\%$, minimum error $\%$, error distribution $\%$ (i.e. frequency of error, Tables 4 and 5), correlation

\begin{tabular}{|c|c|c|c|c|}
\hline $\begin{array}{l}\text { Network } \\
\text { architecture }\end{array}$ & $\begin{array}{l}\text { Data } \\
\text { set }\end{array}$ & MSE & $\begin{array}{c}\text { Biogas } \\
\text { production } \\
\text { correlation }\end{array}$ & Error: \% \\
\hline \multirow[t]{2}{*}{$4-3-1$} & Test & 0.023600 & 0.4327 & $-3 \cdot 8386$ \\
\hline & Entire & & 0.5385 & 0.7066 \\
\hline \multirow[t]{2}{*}{$4-5-1$} & Test & 0.007350 & 0.9100 & -0.8828 \\
\hline & Entire & & 0.9256 & $-0 \cdot 2330$ \\
\hline \multirow[t]{2}{*}{$4-7-1$} & Test & 0.00156 & 0.9863 & $0 \cdot 1312$ \\
\hline & Entire & & 0.9922 & $0 \cdot 3581$ \\
\hline \multirow[t]{2}{*}{$4-10-1$} & Test & $5.76 \times 10^{-4}$ & 0.9849 & $0 \cdot 2463$ \\
\hline & Entire & & 0.9929 & -0.0196 \\
\hline \multirow[t]{2}{*}{$4-11-1$} & Test & $1.42 \times 10^{-4}$ & 0.9976 & 0.2121 \\
\hline & Entire & & 0.9976 & $0 \cdot 1605$ \\
\hline \multirow[t]{2}{*}{$4-12-1$} & Test & $5.70 \times 10^{-5}$ & 0.9948 & $0 \cdot 1963$ \\
\hline & Entire & & 0.9977 & $0 \cdot 1209$ \\
\hline \multirow[t]{2}{*}{ 4-13-1 } & Test & $4.80 \times 10^{-5}$ & 0.9969 & 0.0478 \\
\hline & Entire & & 0.9981 & 0.0362 \\
\hline \multirow[t]{2}{*}{ 4-15-1 } & Test & $2.20 \times 10^{-5}$ & 0.9024 & 0.0147 \\
\hline & Entire & & 0.9520 & 0.0181 \\
\hline \multirow[t]{2}{*}{$4-17-1$} & Test & $6.00 \times 10^{-6}$ & 0.9996 & 0.0036 \\
\hline & Entire & & 0.9985 & 0.0049 \\
\hline \multirow[t]{2}{*}{$4-19-1$} & Test & $1.30 \times 10^{-5}$ & 0.9991 & $0 \cdot 1844$ \\
\hline & Entire & & 0.9979 & $0 \cdot 1115$ \\
\hline \multirow[t]{2}{*}{$4-21-1$} & Test & $7 \cdot 40 \times 10^{-5}$ & 0.9756 & 0.5754 \\
\hline & Entire & & 0.9799 & 0.5002 \\
\hline \multirow[t]{2}{*}{$4-23-1$} & Test & $1.00 \times 10^{-6}$ & 0.9989 & 0.26500 \\
\hline & Entire & & 0.9992 & $0 \cdot 3189$ \\
\hline \multirow[t]{2}{*}{$4-25-1$} & Test & $1.00 \times 10^{-6}$ & 0.9956 & $0 \cdot 1482$ \\
\hline & Entire & & 0.9955 & $0 \cdot 2901$ \\
\hline \multirow[t]{2}{*}{$4-27-1$} & Test & $1.00 \times 10^{-6}$ & 0.9609 & 0.0453 \\
\hline & Entire & & 0.9663 & 0.0294 \\
\hline \multirow[t]{2}{*}{$4-31-1$} & Test & $2 \cdot 10 \times 10^{-5}$ & 0.9987 & -0.0369 \\
\hline & Entire & & 0.9994 & -0.0405 \\
\hline
\end{tabular}

Table 4. Correlation coefficient between network predictions and experimental values using the test and entire data set of different network architectures and trained output parameters of biogas production. Optimum values shown in bold

coefficient and on the convergence of the entire data set within the specified/expected/reasonable error range. Table 6 shows the partial sample of tested data, forecast data and possibilities of error in the predictions of the biogas yield of the optimum architecture model 4-17-1. Thus, networks having a single hidden layer of 17 neurons are trained with LevenbergMarquardt algorithm which has been selected as the optimum network model. It is also observed that the increase in the number of neurons in the single hidden layers has important improvement on the performance of the networks and thereby the performance slowly degrades. The association between the predicted values of the optimum neural network model and 


\begin{tabular}{|c|c|c|c|c|c|c|c|}
\hline \multirow[b]{2}{*}{ Network architecture } & \multicolumn{7}{|c|}{ Number of error frequency } \\
\hline & 4-10-1 & 4-13-1 & 4-15-1 & 4-17-1 & $4-19-1$ & $4-22-1$ & $4-25-1$ \\
\hline \multicolumn{8}{|l|}{ Error frequency range } \\
\hline$<-50$ & $0 \cdot 14$ & 0.00 & 0.00 & 0.00 & 0.00 & 0.00 & 0.00 \\
\hline-50 to -45 & 0.07 & 0.00 & 0.00 & 0.00 & 0.00 & 0.00 & 0.00 \\
\hline-45 to -40 & 0.00 & 0.00 & 0.00 & 0.00 & 0.00 & 0.07 & 0.07 \\
\hline-40 to -35 & 0.00 & 0.00 & 0.00 & 0.00 & 0.00 & 0.00 & 0.00 \\
\hline-35 to -30 & 0.00 & 0.00 & 0.00 & 0.00 & 0.00 & 0.00 & 0.00 \\
\hline-30 to -25 & $0 \cdot 14$ & 0.00 & 0.00 & 0.00 & 0.00 & $0 \cdot 14$ & 0.00 \\
\hline-25 to -20 & 0.00 & 0.00 & 0.00 & 0.00 & 0.00 & 0.00 & 0.00 \\
\hline-20 to -16 & 0.00 & 0.60 & 0.00 & 0.00 & 0.00 & 0.00 & 0.00 \\
\hline-16 to -12 & $1 \cdot 55$ & $1 \cdot 27$ & 0.00 & 0.00 & 0.00 & 0.00 & 0.00 \\
\hline-12 to -8 & $2 \cdot 06$ & $1 \cdot 41$ & 0.60 & 0.07 & 0.00 & 0.27 & 0.27 \\
\hline-8 to -4 & $4 \cdot 74$ & 1.92 & 0.91 & 0.17 & 0.48 & 0.41 & $2 \cdot 13$ \\
\hline-4 to 4 (percentage of data within this range) & $82 \cdot 27$ & $89 \cdot 54$ & $95 \cdot 12$ & 98.97 & $98 \cdot 28$ & 98.08 & $86 \cdot 88$ \\
\hline $4-8$ & $5 \cdot 15$ & $2 \cdot 88$ & 2.06 & 0.45 & 0.27 & 0.41 & $6 \cdot 66$ \\
\hline $8-12$ & $4 \cdot 53$ & $1 \cdot 37$ & 0.87 & 0.34 & $0 \cdot 14$ & 0.27 & $6 \cdot 32$ \\
\hline $12-16$ & $1 \cdot 27$ & 0.91 & 0.44 & 0.00 & 0.00 & 0.00 & 0.69 \\
\hline $16-20$ & 0.27 & 0.50 & 0.00 & 0.00 & 0.00 & 0.00 & 0.41 \\
\hline $20-25$ & 0.14 & 0.40 & 0.00 & 0.00 & 0.00 & 0.00 & 0.55 \\
\hline $25-30$ & 0.00 & 0.00 & 0.00 & 0.00 & 0.00 & 0.00 & 0.27 \\
\hline 30-35 & 0.00 & 0.00 & 0.00 & 0.00 & 0.00 & 0.00 & 0.00 \\
\hline $35-40$ & 0.14 & 0.00 & 0.00 & 0.00 & 0.14 & 0.00 & 0.14 \\
\hline 40-45 & 0.00 & 0.00 & 0.00 & 0.00 & 0.00 & 0.00 & 0.00 \\
\hline $45-50$ & 0.00 & 0.00 & 0.00 & 0.00 & 0.00 & 0.00 & 0.00 \\
\hline$>50$ & 0.00 & 0.00 & 0.00 & 0.00 & 0.27 & 0.00 & 0.00 \\
\hline
\end{tabular}

Table 5. Comparison of error distribution in terms of error frequency of the entire data set for the selected network architecture of biogas yield from food waste and cow dung. Optimum values shown in bold

the experimental data for the calculation of biogas yield using the partial sample data sets is shown in Figure 3. This shows that the developed model has high accuracy for predicting the biogas yield of food waste and cow dung mixed digesters in terms of the plant $\mathrm{pH}$ level, age of the digester and plant temperature. The variation of the plant $\mathrm{pH}$ level, age of the digester and plant temperature against the percentage of food waste and cow dung digester is shown in Figures 4-6 predicted by the respective optimised ANN model. Further, Table 6 shows the results of the comparison between experimental and prediction from 4-17-1 architecture for food waste and cow dung digester. It was clearly observed from Figures 4-6 and Table 6 that the calculation of biogas yield was possible. It has been concluded that the ANN model could predict the biogas yield.

\subsection{Quantitative analysis}

From Figures 4-6 it is evident that all selected process parameters interact with each other and their interaction regulates the overall biogas output values suggesting different concentrations of fermentation process parameters which are discussed as follows.

\subsubsection{Influence of $\mathrm{pH}$ on the biogas yield}

Figure 4 depicts the interactive influence of $\mathrm{pH}$ of the medium with food waste to cow dung ratio. It is clear from the fact that both the parameters are having different pressures on the metabolism of the microbial consortia used. The $\mathrm{pH}$ behaviour of the cultures shows a range of $6 \cdot 0-8 \cdot 0$ during the highest point of biogas production. Sensitivity of methanogens to medium $\mathrm{pH}$ has been reported (Nagamani and Ramasamy, 1999) with a possibility of metabolic repression at an optimum biogas yield at $\mathrm{pH}$ between $6 \cdot 7$ and $7 \cdot 1$ and a satisfactory biogas production at $\mathrm{pH}$ between 6.6 and 7.6 has been reported (Nagamani and Ramasamy, 1999). In the end, the drift in $\mathrm{pH}$ in the digester is a function of the nature and concentration of the various co-substrates and the cell metabolic activities 


\begin{tabular}{|c|c|c|c|c|c|c|}
\hline \multirow[b]{2}{*}{ SI. number } & \multirow[b]{2}{*}{$\%$ food waste } & \multirow[b]{2}{*}{ Age: d } & \multirow[b]{2}{*}{ Temperature: ${ }^{\circ} \mathrm{C}$} & \multirow[b]{2}{*}{$\mathrm{pH}$} & \multicolumn{2}{|c|}{ Biogas production } \\
\hline & & & & & Observed: $\mathrm{ml} / \mathrm{g}$ VS & Predicted: $\mathrm{ml} / \mathrm{g}$ VS \\
\hline 1 & 0 & 17 & 37 & $6 \cdot 7$ & $248 \cdot 748$ & $247 \cdot 633$ \\
\hline 2 & 0 & 21 & 39 & $7 \cdot 1$ & $260 \cdot 324$ & $259 \cdot 209$ \\
\hline 3 & 10 & 27 & 38 & $6 \cdot 9$ & $293 \cdot 850$ & $292 \cdot 735$ \\
\hline 4 & 10 & 31 & 35 & $6 \cdot 3$ & $282 \cdot 836$ & $283 \cdot 951$ \\
\hline 5 & 25 & 16 & 39 & $7 \cdot 1$ & $262 \cdot 724$ & $261 \cdot 609$ \\
\hline 6 & 25 & 37 & 37 & $6 \cdot 7$ & $292 \cdot 658$ & $291 \cdot 543$ \\
\hline 7 & 35 & 19 & 37 & $6 \cdot 7$ & $265 \cdot 678$ & $264 \cdot 563$ \\
\hline 8 & 35 & 39 & 38 & $6 \cdot 9$ & $299 \cdot 766$ & $298 \cdot 651$ \\
\hline 9 & 50 & 17 & 36 & $6 \cdot 5$ & $276 \cdot 057$ & 274.942 \\
\hline 10 & 50 & 40 & 39 & $7 \cdot 1$ & $309 \cdot 882$ & $308 \cdot 767$ \\
\hline 11 & 60 & 31 & 39 & $7 \cdot 1$ & $329 \cdot 969$ & $331 \cdot 084$ \\
\hline 12 & 60 & 33 & 38 & $6 \cdot 9$ & $331 \cdot 189$ & $332 \cdot 304$ \\
\hline 13 & 70 & 25 & 37 & $6 \cdot 7$ & $366 \cdot 974$ & 368.089 \\
\hline 14 & 70 & 27 & 38 & $6 \cdot 9$ & $361 \cdot 594$ & $362 \cdot 709$ \\
\hline 15 & 75 & 25 & 39 & $7 \cdot 1$ & $373 \cdot 138$ & $374 \cdot 253$ \\
\hline 16 & 75 & 28 & 38 & $6 \cdot 9$ & $357 \cdot 134$ & $358 \cdot 249$ \\
\hline 17 & 85 & 21 & 37 & $6 \cdot 7$ & $354 \cdot 391$ & $355 \cdot 506$ \\
\hline 18 & 85 & 23 & 36 & $6 \cdot 5$ & $355 \cdot 518$ & 356.633 \\
\hline 19 & 95 & 16 & 35 & $6 \cdot 3$ & $316 \cdot 162$ & $317 \cdot 277$ \\
\hline 20 & 95 & 30 & 35 & $6 \cdot 3$ & $335 \cdot 931$ & $337 \cdot 046$ \\
\hline 21 & 100 & 39 & 34 & $6 \cdot 1$ & $345 \cdot 750$ & $346 \cdot 865$ \\
\hline 22 & 100 & 40 & 35 & $6 \cdot 3$ & $343 \cdot 529$ & $344 \cdot 644$ \\
\hline
\end{tabular}

VS, volatile solids

Table 6. Partial sample predicted data

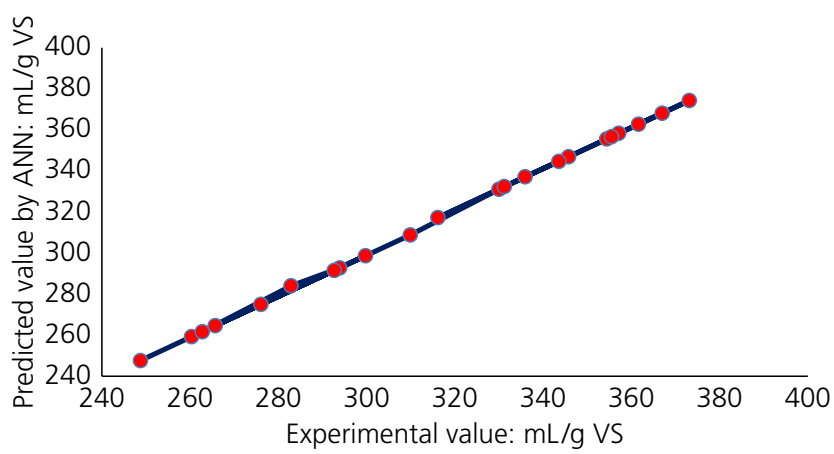

Figure 3. Correlation chart for experimental and ANN predicted biogas yield data

(Gueguim Kana et al., 2012). Ideally, continuous monitoring of the $\mathrm{pH}$ level in anaerobic digestions should be adopted, as it generates more reliable process information. From Figure 4 it is clear that the satisfactory range of biogas production was achieved with the $\mathrm{pH}$ ranging from 6 to 8 .

\subsubsection{Influence of temperature on biogas yield}

Temperature is an important factor that determines the rate of digestion. Most of the digesters operated in the mesophilic range $\left(30-40^{\circ} \mathrm{C}\right)$, but it is also possible to operate the digesters in the thermophilic range $\left(\sim 55^{\circ} \mathrm{C}\right)$ but with higher working costs, lower process stability and with more structural requirements (Chen et al., 2010; Kiely, 1998). From Figure 5, it is clear that the biogas yield has increased gradually with respect to temperature. For the temperature range at $30-45^{\circ} \mathrm{C}$, the biogas yield is increased for the food waste and cow dung digester. It is clearly observed from Figure 5 in the mesophilic range that more biogas yield can be obtained. It is concluded that the mesophilic range could turn over more biogas yield without any additional sources.

\subsubsection{Influence of the age of the plant on biogas yield}

From all the range of studies of carbon sources, its influence is more effective as the food waste dominates in the fermentation media suggestive of the presence of food as a carbon source. It is clear from Figure 6 that biogas yield increases with increase 
Municipal Engineer

Volume 170 Issue ME4
Optimising biogas from food waste using

a neural network model

Palaniswamy, Ramesh, Sivasankaran and

Kathiravan

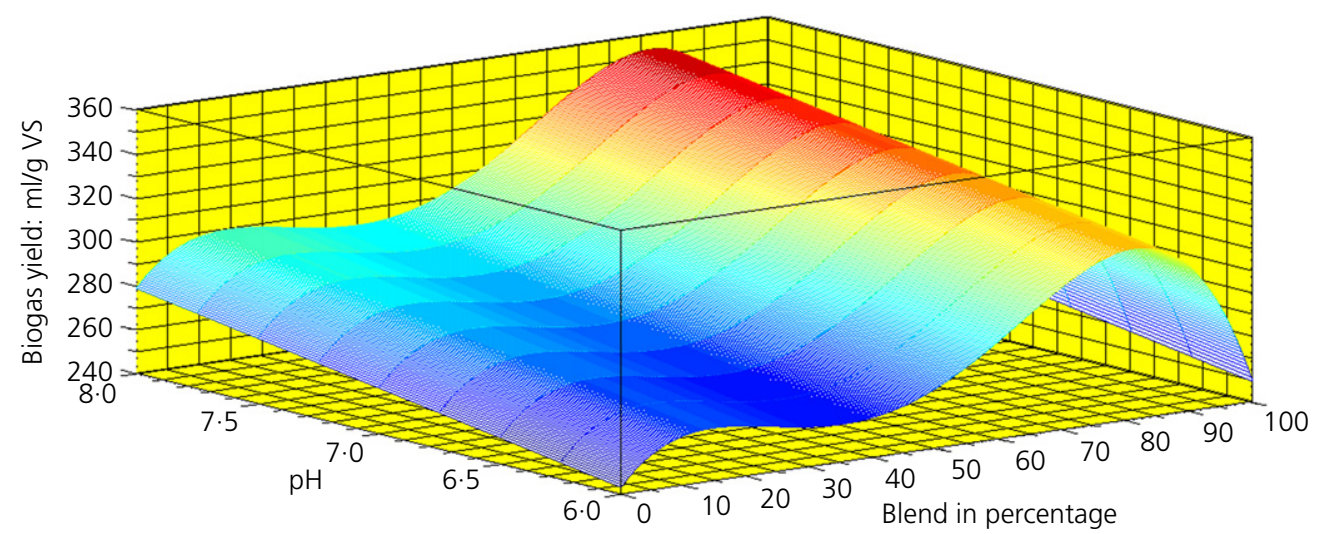

Figure 4. Variation in biogas production as a function of $\mathrm{pH}$ and food waste blend with cow dung trained and predicted by a neural network model

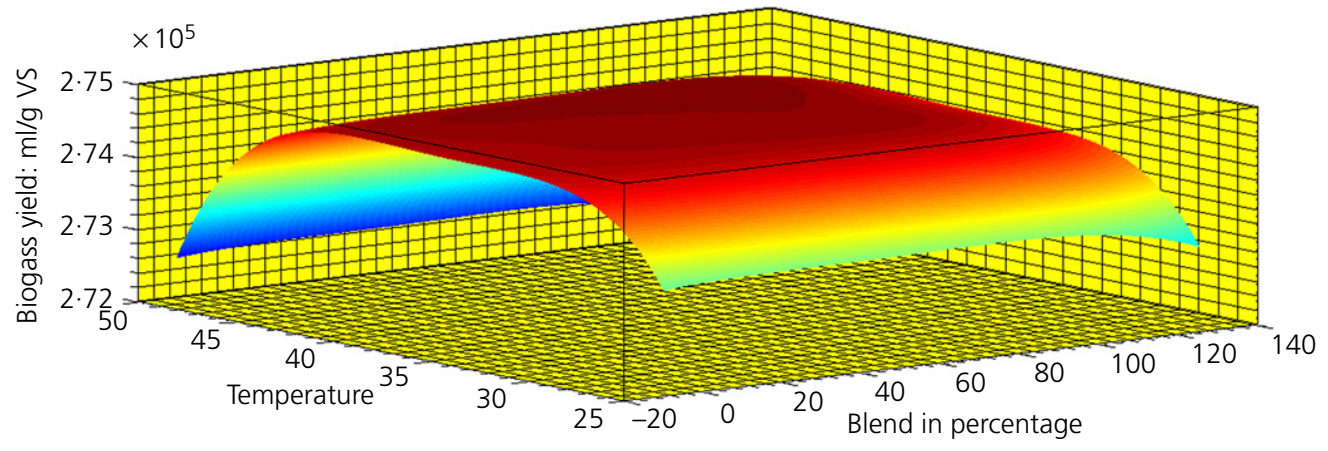

Figure 5. Variation in biogas production as a function of temperature and food waste blend with cow dung trained and predicted by a neural network model

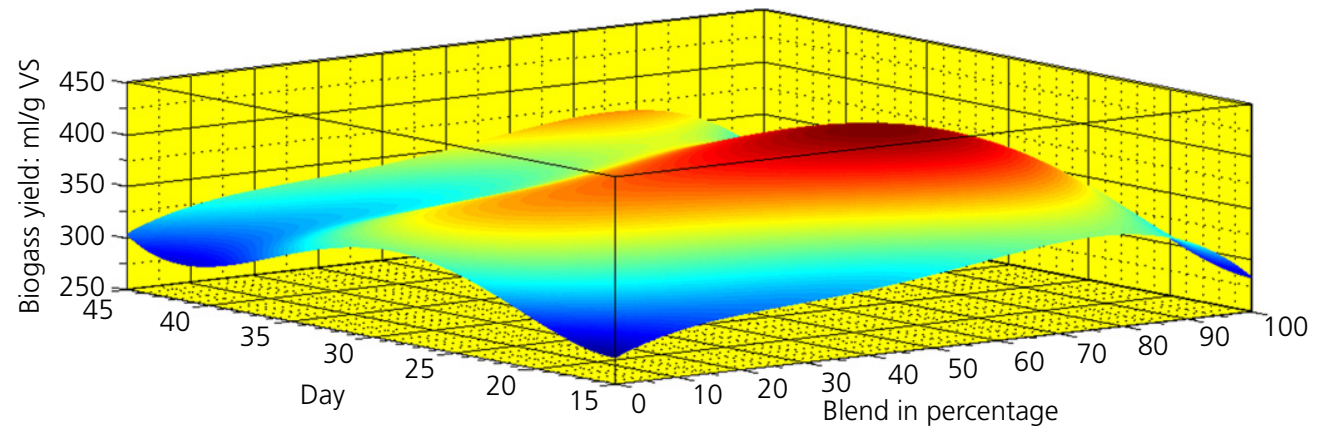

Figure 6. Variation in biogas production as a function of plant age and food waste blend with cow dung trained and predicted by a neural network model 
in age of the plant and maximum biogas efficiency $(375 \mathrm{ml} / \mathrm{g}$ volatile solids (VS)) is observed with $20-35 \mathrm{~d}$ grown culture. From the earlier reports (Gueguim Kana et al., 2012) it is observed that the biogas is effectively produced in the presence of carbon and nitrogen which is seen to be in the ratio 25-30:1. This regulates the metabolic processes of the microbial combination leading to biogas production. Nevertheless, when the mixture of this food waste has been utilised as a carbon source, the biogas production is observed with an increase in food waste absorption by up to $70-80 \%$ of the total carbon source.

Compared with any other bio stuff wastes and farm wastes, the food waste which is a composition of various kinds of wastes will yield $15 \%$ greater quantity of biogas. The dung is a waste from the animal after utilising maximum energy during digestion. So the biogas produced is less compared with food waste. In previously reported carbon source range (Curry and Pillay, 2012) its influence is more successful as the food waste concentration dominates the fermentation medium suggesting that the presence of food as a carbon source elevates the metabolic processes leading to biogas production.

\section{Conclusion}

This study shows that BPNN architecture is a technique that can be efficiently used to predict the biogas yield from food waste. Different types of multilayer BPNN architecture were trained and used and the BPNN with one unseen layer having 17 neurons, trained with Levenberg-Marquardt algorithm was found to be the optimum network model for biogas yield (4-17-1). It is believed that this approach can be used to forecast the biogas yield from food waste. In anaerobic digestion, the digester D17 had the highest biogas performance level of $375 \mathrm{ml} / \mathrm{g}$ VS in the 25th day of digestion, with the substrate profile of $80 \%$ food waste and $20 \%$ cow dung at a temperature range of $30-40^{\circ} \mathrm{C}$. On the basis of the above results, it is concluded that biogas fabrication from dining waste and vegetable waste combination is highly attractive and can be used effectively at institutional level with the most favourable temperature range thereby reducing the use of fossil fuels.

\section{REFERENCES}

Abu Qdais H, Bani Hani K and Shatnawi N (2010) Modeling and optimization of biogas production from a waste digester using artificial neural network and genetic algorithm. Resources Conservation and Recycling 54(6): 359-363.

Avicenna, Mel M, Ihsan SI and Setyobudi RH (2015) Process improvement of biogas production from anaerobic co-digestion of cow dung and corn husk. Procedia Chemistry 14: 91-100.

Bajon Fernandez Y, Soares A, Villa R, Vale P and Cartmell E (2014) Carbon capture and biogas enhancement by carbon dioxide enrichment of anaerobic digesters treating sewage sludge or food waste. Bioresource Technology 159: 1-7.

Chen X, Romano RT and Zhang R (2010) Anaerobic digestion of food wastes for biogas production. International Journal of Agricultural and Biological Engineering 3(4): 61-72.

Curry N and Pillay P (2012) Biogas prediction and design of a food waste to energy system for the urban environment. Renewable Energy 41: 200-209.

Gueguim Kana EB, Oloke JK, Lateef A and Adesiyan MO (2012) Modeling and optimization of biogas production on saw dust and other co-substrates using artificial neural network and genetic algorithm. Renewable Energy 46: 276-281.

Haider MA, Pakshirajan K, Singh A and Chaudhry S (2008) Artificial neural network genetic algorithm approach to optimize media constituents for enhancing lipase production by a soil microorganism. Applied Biochemistry and Biotechnology 144(3): 225-235.

Hanreich A, Schimpf U, Zakrewski M et al. (2013) Metagenome and metaproteme analyses of microbal communities in mesophilic biogas-producing anaerobic batch fermentation indicate concerted plant carbohydrate degradation. Systematic and Applied Microbiology 36(5): 330-338.

Kiely G (1998) Environmental Engineering, International edn. Irwin, McGraw-Hill, Boston, MA, USA.

Kumar YS, Prakasam RS and Reddy OVS (2009) Optimisation of fermentation conditions for mango wine production by employing response surface methodology. International Journal of Food Science and Technology. 44(11): 2320-2327.

Labatut RA, Angenent LT and Scott NR (2014) Conventional mesophilic vs. thermophilic anaerobic digestion: a trade-off between performance stability?. Water Research $\mathbf{5 3}$ : 249-258.

Lai CM, Ke GR and Chung MY (2009) Potentials of food wastes for power generation and energy conservation in Taiwan. Renewable Energy 34(1): 1913-1915.

Martinez E, Marcos A, Al-Kassir A, Jaramillo MA and Mohamad AA (2012) Mathematical model of a laboratoryscale plant for slaughterhouse effluents biodigestion for biogas production. Applied Energy 95: 210-219.

Mezzullo WG, McManus MC and Hammond GP (2013) Life cycle assessment of a small-scale anaerobic digestion plant from cattle waste. Applied Energy 102: 657-664.

Middleton RS and Eccles JK (2013) The complex future of $\mathrm{CO}_{2}$ capture and storage: variable electricity generation and fossil fuel power. Applied Energy 108: 66-73.

Nagamani B and Ramasamy K (1999) Biogas production technology: an Indian perspective. Current Science 77: $44-45$.

Prakasham RS, Sathish T, Brahmaiah P et al. (2009) Biohydrogen production from renewable agriculture waste blend: optimization using mixer design. International Journal of Hydrogen Energy 34: 6143-6148. 
Prakasham RS, Sathish T and Brahmaiah P (2011) Imperative role of neural networks coupled genetic algorithm on optimization of biohydrogen yield. International Journal of Hydrogen Energy 36: 4332-4339.

Rongpin LS, Chen XL, Saifullah L and Yanfeng H (2009) Anaerobic co-digestion of kitchen waste with cattle manure for biogas production. Energy and Fuels 23: 2225-2229.

Sitorus B, Sukandar and Panjaitan SD (2013) Biogas recovery from anaerobic digestion process of mixed fruit-vegetable wastes. Energy Procedia 32: 176-182.

Stantscheff R, Kuever J, Rabenstein A et al. (2014) Isolation and differentiation of methanogenic Archaea from mesophilic corn-fed on-farm biogas plants with special emphasis on the genus Methanobacterium. Applied Environmental Biotechnology 98(12): 5719-5735.

Tchobanoglous G and Burton FL (1991) Waste-Water Engineering: Treatment Disposal and Reuse, 3rd edn. McGraw-Hill, New York, NY, USA.
Trisakti B, Manalu V, Taslim I and Turmuzi M (2015) Acidogenesis of palm oil mill effluent to produce biogas: effect of hydraulic retention time and $\mathrm{pH}$. Procedia Social and Behavioral Sciences 195: 2466-2474.

Vijay KG and Rintu B (2010) Evolutionary and swarm intelligence-based approaches for optimization of lipase extraction from fermented broth. Engineering in Life Sciences 10(3): 265-273.

Wang J and Wan W (2009) Factors influencing fermentative hydrogen production: a review. International Journal of Hydrogen Energy 34(2): 799-811.

Wichern M, Gehring T, Fischer K et al. (2009) Mono fermentation of grass silage under mesophilic conditions: measurements and mathematical modeling with ADM. Bioresource Technology 100: 1675-1681.

Zhang R, El-Mashad HM, Hartman K, Wang F, Liu G, Choate C and Gamble P (2007) Characterization of food waste as feedstock for anaerobic digestion. Bioresource Technology 98: 929-936.

\section{HOW CAN YOU CONTRIBUTE?}

To discuss this paper, please email up to 500 words to the editor at journals@ice.org.uk. Your contribution will be forwarded to the author(s) for a reply and, if considered appropriate by the editorial board, it will be published as discussion in a future issue of the journal.

Proceedings journals rely entirely on contributions from the civil engineering profession (and allied disciplines). Information about how to submit your paper online is available at www.icevirtuallibrary.com/page/authors, where you will also find detailed author guidelines. 